\title{
Determination of Silicate in Waste and Recycled Engine Coolants using Capillary Electrophoresis
}

FACULTY OF

SCIENCE

Charles University
Andre Schaum ${ }^{1,2}$ and Tomáš Kř́žek ${ }^{1}$

1. Department of Analytical Chemistry, Faculty of Science, Charles University, Prague, Czechia 2. Department of Chemistry, Concordia College, Moorhead, Minnesota
CONCORDIA COLLEGE

\section{Objective}

Develop a robust capillary electrophoresis method for the detection of silicate in waste and recycled engine coolants.

\section{Introduction}

aste Coolant Recycling

- Glycol-based coolants are ubiquitous in automotive engines and industrial machinery ${ }^{1}$

- Recent European Union legislature has driven an increase in the recycling of waste coolants ${ }^{2}$

Silicate in Engine Coolants

- Silicate is considered the most effective corrosion inhibitor for metal surfaces in engines ${ }^{1}$

- Complex equilibria between solid colloids and soluble monomers impose need for organosilicate stabilizers ${ }^{1}$

- Capillary electrophoresis (CE) has proven to be an effective technique for silicate and coolant additive analyse ${ }^{3}$ $\mathrm{SiO}_{2}(\mathrm{~s})+2 \mathrm{H}_{2} \mathrm{O} \rightleftharpoons \mathrm{Si}(\mathrm{OH})_{4}(\mathrm{aq}) \rightleftharpoons\left(\mathrm{HO}_{3} \mathrm{SiO}^{-}(\mathrm{aq})\right.$ $(\mathrm{HO})_{3} \mathrm{SiO}^{-}+\mathrm{HOSi}(\mathrm{OH})_{3} \rightleftharpoons(\mathrm{HO})_{3} \mathrm{SiOSi}(\mathrm{OH})_{3}+\mathrm{OH}^{-}$ $m(\mathrm{HO})_{3} \mathrm{SiO}^{-}+(\mathrm{HO})_{3}(\mathrm{SiOSi})_{n}(\mathrm{OH})_{3} \rightleftharpoons$ oligomer $+n \mathrm{OH}^{-}$

$\mathrm{m}(\mathrm{HO})_{3} \mathrm{SiO}^{-}+$oligomer $\rightleftharpoons$ polymer colloid Figure 1. Equilibria between soluble silicate and insoluble polymer colloids.

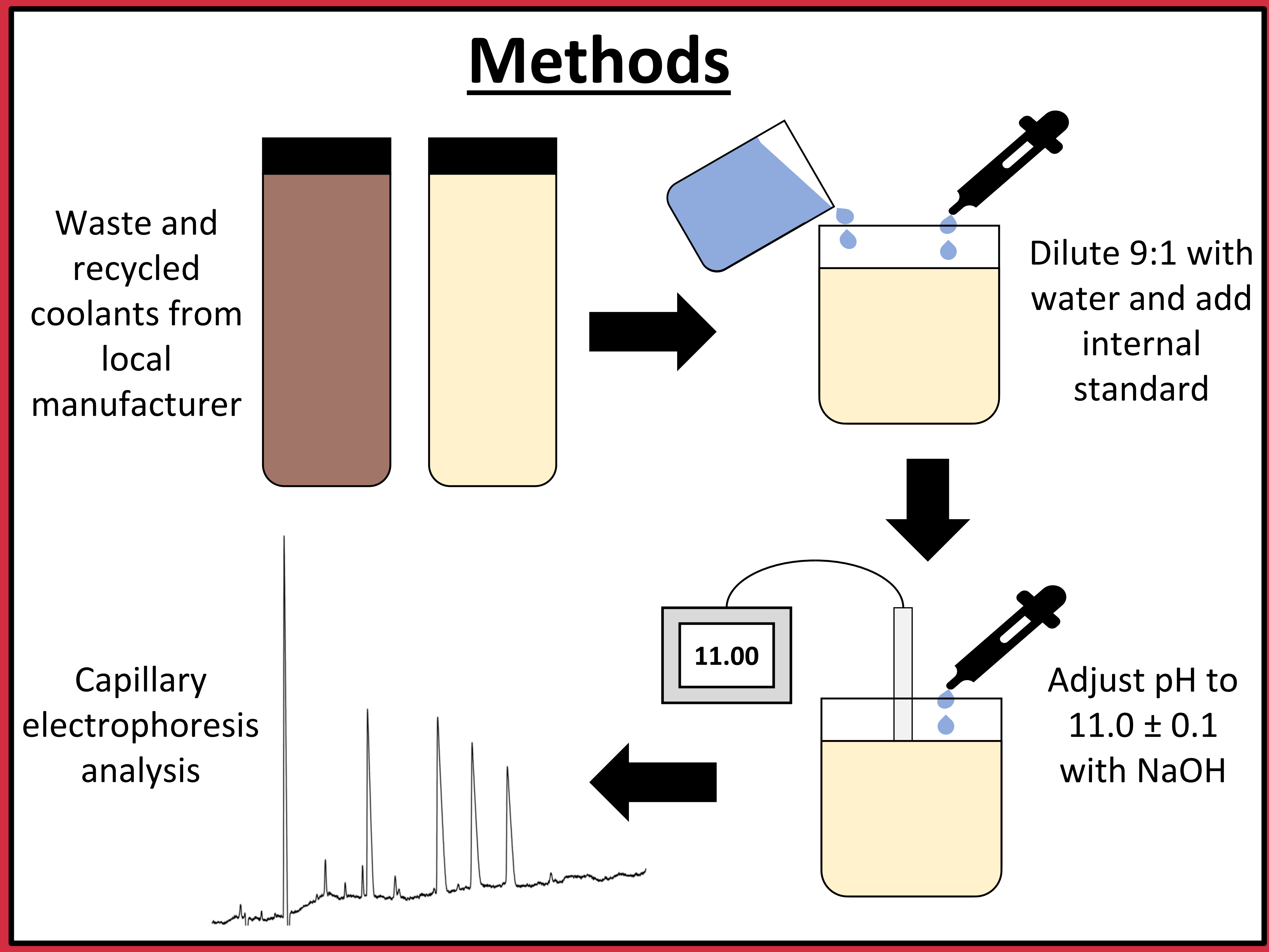

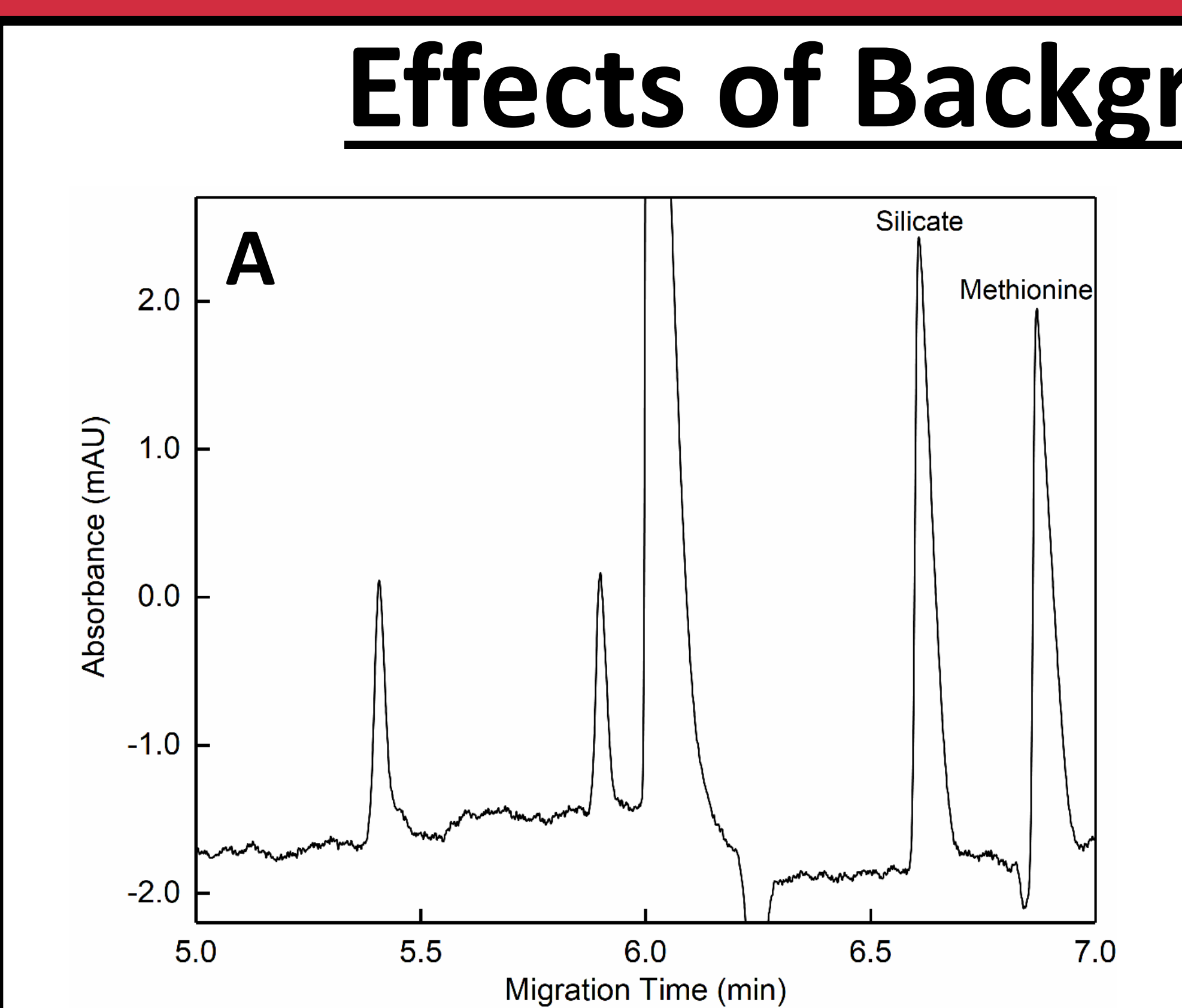
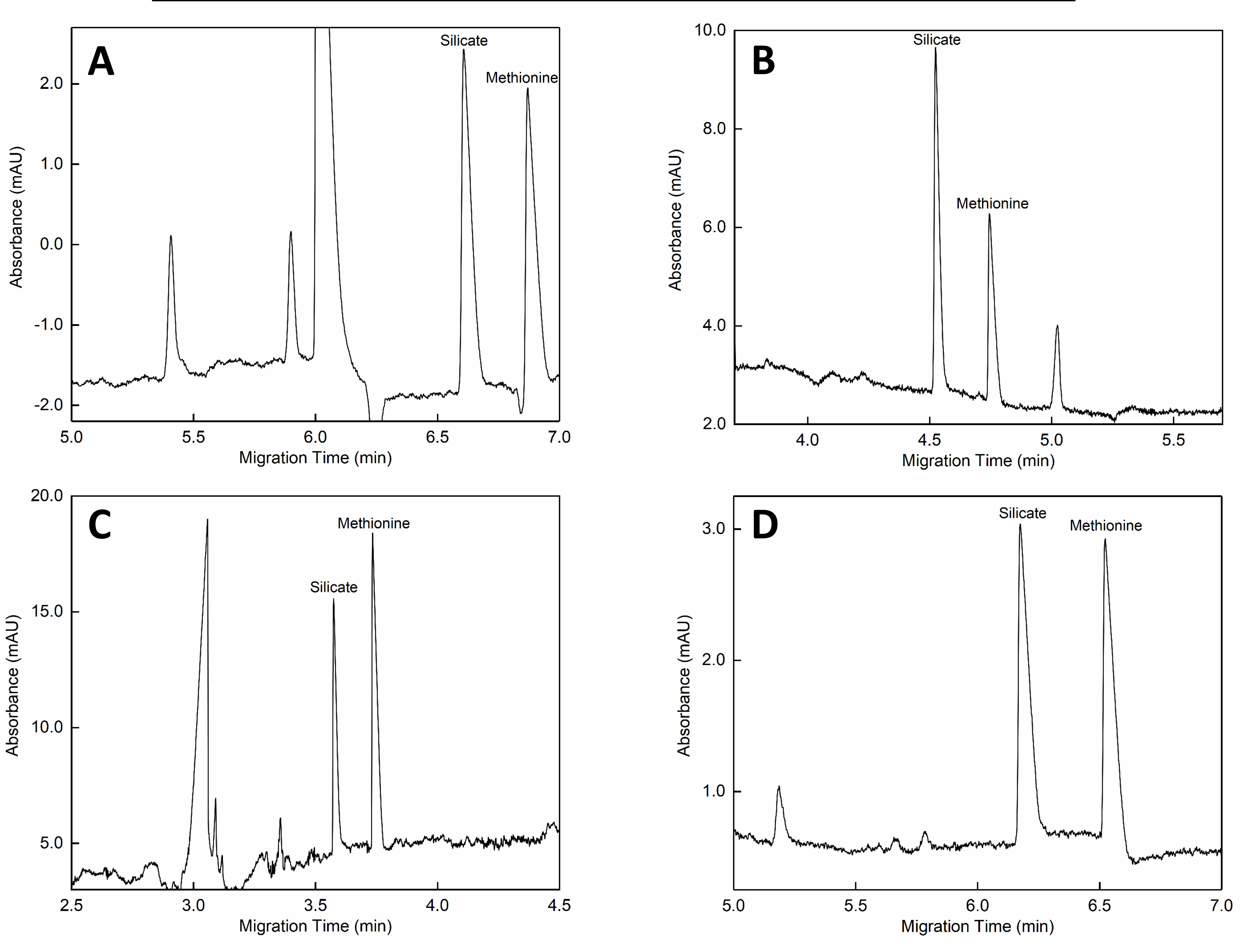

Figure 2. Electropherograms of $10 \mathrm{mg} \mathrm{L}^{-1}$ silicate standard with $20 \mathrm{mg} \mathrm{L}^{-1}$ methionine using A) 2,6 pyridinedicarboxylic acid, B) sodium benzenesulfonate, C) tyrosine, and D) $\mathrm{Na}_{2} \mathrm{CrO}_{4}$ background electrolyte

\section{Method Validation}

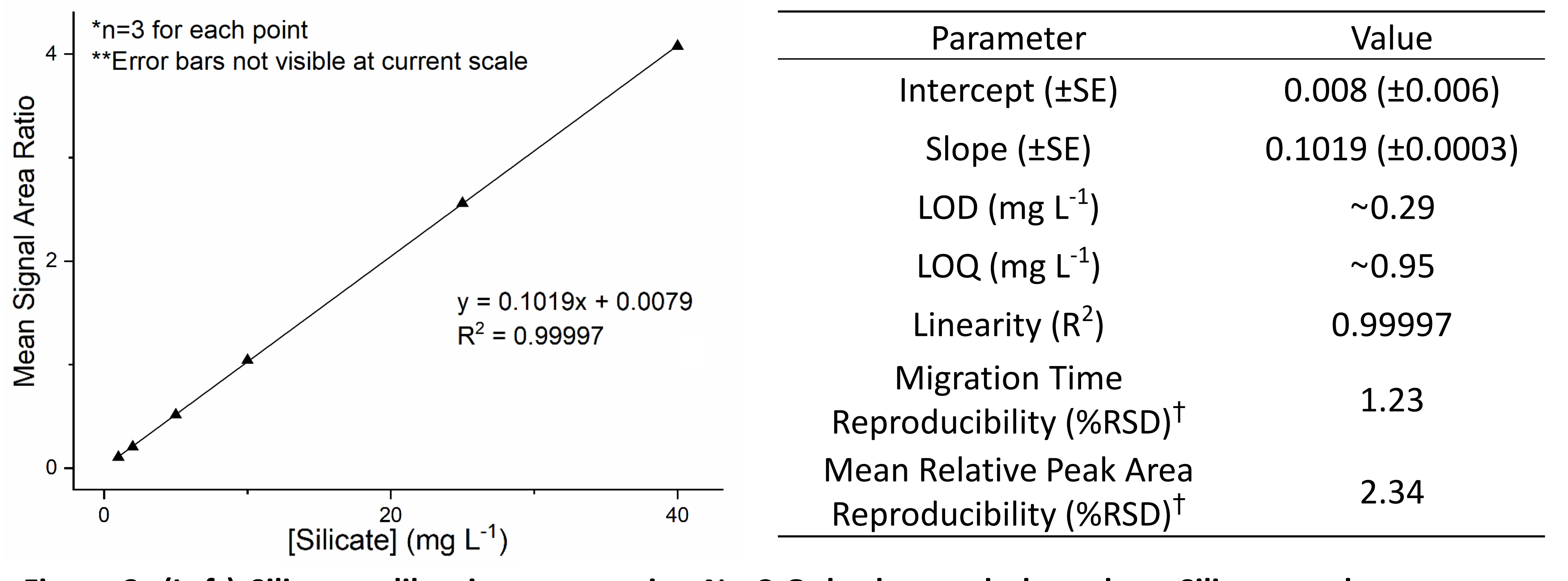

figure 3. (Left) Silicate calibration curve using

Reproducibility (\%RSD)

normalized to Is and

Table 1. (Right) Analytical figures of merit using $\mathrm{Na}_{2} \mathrm{CrO}_{4}$ background electrolyte, ${ }^{\mathrm{t}} \mathrm{n}=18$.

\section{Preliminary Coolant Results}
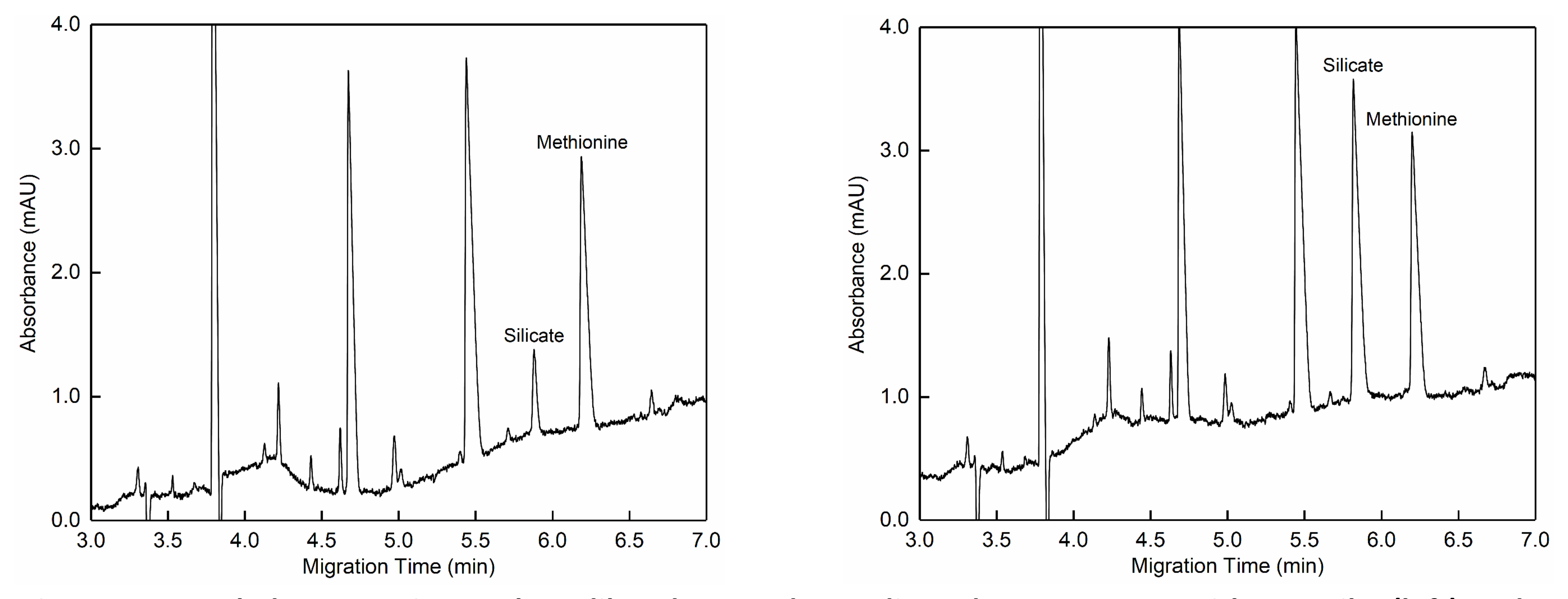

(50 with $10 \mathrm{mg} \mathrm{t}^{-1}$ silicate added (right). Spike recovery was calculated to be $103.4 \%$

\section{Conclusions}

- Sodium chromate background electrolyte shows highest potential for use in coolant recycling industry

- Viability is limited by significant matrix effects imposed by some coolant samples

- Sodium benzenesulfonate background electrolyte provided desirable performance, but is incompatible with most coolants

- If decomposition is mitigated, tyrosine may prove to be superior background electrolyte

- Higher sensitivity and shorter migration time observed with tyrosine background electrolyte

\section{Future Directions}

- Attempt preconcentration or purification techniques (e.g. SPE) to minimize matrix effects in coolant samples

- Investigate effects of organosilicate stabilizer on coolant analysis

- High $\mathrm{pH}$ and/or temperature treatment to release bound silicate

- Analysis of industrial inhibitor mixture

- If method proves unsuccessful, contactless conductivity detection may also be explored

\section{Acknowledgements}

We would like to acknowledge support from National Science Foundation (NSF) IRES 1658615. Any opinions, findings, and conclusions or recommendations expressed in this material are those of the author(s) and do not necessarily reflect the views of the NSF. We would also like to thank the following:

- Charles University Faculty of Science and Department of Analytical Chemistry

- University of North Dakota and Dr. Alena Kubátová

\section{UN}

\section{References}

Schwartz, S. A. Silicate Stabilization Studies in Propylene Glycol. In Engine Coolant Testing: Fourth Volume, ASTM STP 1335; R. E. Beal, American Society for Testing Materials, 1999, pp 327-351.

Enger S 